\title{
Effect of nutrition on testicular growth and plasma concentrations of gonadotrophins, testosterone and insulin-like growth factor I (IGF-I) in pubertal male Soay sheep
}

\author{
C. L. Adam and P. A. Findlay \\ Molecular Neuroendocrinology Unit, Rowett Research Institute, Bucksburn, Aberdeen AB21 9SB, UK
}

\begin{abstract}
Nutritional effects on puberty were studied in Soay rams. Testicular growth is initiated at birth in April and testes reach maximum size in October. Groups of eight lambs were fed for 18 weeks, starting in August, a ration that restricted growth (Group R), the same diet ad libitum (Group F), or a restricted diet for 8 weeks followed by ad libitum feeding (Group R/F). Seasonal increases of plasma FSH, testis size, sexual skin flush and plasma testosterone occurred with similar timing but reduced magnitude in Group R compared with Group F lambs. Testis size and sexual skin flush peaked in all groups at 11 weeks (30 October); the testes of Group $\mathrm{F}$ animals were larger before the peak, but similar in size thereafter, compared with testes from Group R/F, and larger throughout the experimental period than testes from Group R. Plasma testosterone was higher in Group F than in Group R lambs from 7 to 17 weeks, but in Group R/F was similar to Group R before 10 weeks (23 October) and similar to Group $\mathrm{F}$ thereafter. Testis size, plasma testosterone, plasma insulin-like growth factor I (IGF-I) and liveweight were positively correlated. Ad libitum feeding in August-September (Group F) stimulated increased plasma FSH and LH above values for Group R, but ad libitum feeding initiated in October did not affect gonadotrophin concentrations (Group R/F). Therefore, the effects of improved nutrition on the hypothalamo-pituitary axis, which may have been mediated by circulating IGF-I, were season- or age-dependent, and those on the testes included direct stimulation, independent of changes in gonadotrophin concentrations. Nutrition modified the intensity, but not the timing, of peak pubertal reproductive activation.
\end{abstract}

\section{Introduction}

It is well established that domesticated male sheep reared on high as opposed to low planes of nutrition attain puberty earlier in life, and that their rate of sexual development is highly dependent on food energy intake and liveweight gain (Dýrmundsson, 1973). Their reproductive neuroendocrine system is highly sensitive to changes in nutrition (Wood et al., 1991a), and photoperiod has minimal influence on the timing of puberty (Wood et al., 1991b). However, breeds of sheep differ substantially in their responses to photoperiod (Lincoln et al., 1990). Sexual activity in Merino rams, for example, is not restricted by photoperiod to rigidly timed seasons, but is highly dependent on diet (Martin et al., 1994); and the timing of puberty in Merino ram lambs depends on their plane of nutrition (Pretorius and Marincowitz, 1968). Conversely, adult rams of the primitive Soay breed show pronounced, photoperiodically driven seasonal cycles of reproductive activity (Lincoln and Short, 1980), and it is not known whether these are modified by nutrition. Nutritional modulation of the adult male reproductive cycle has been reported in another seasonal ruminant, the cashmere goat (Walkden-Brown et al.,

Received 28 February 1997
1994). However, it is not known how nutrition may modify pubertal male reproductive development in characteristically photosensitive breeds.

In Soay ram lambs, testicular growth is initiated at birth in April and testes reach maximum size 6 months later in October (Lincoln and Baker, 1995). The present objective was to describe in such lambs the effects of restricted versus unrestricted feeding, initiated during the final 2-3 months of pubertal development, on testicular growth and circulating concentrations of gonadotrophins and testosterone. Plasma concentrations of insulin-like growth factor I (IGF-I) were also measured since there is evidence that they are high at puberty in male ruminants (Adam et al., 1995) and may provide critical nutritional feedback to the pubertal reproductive axis in rats (Hiney et al., 1996).

\section{Materials and Methods}

\section{Animals and treatments}

Twenty-four Soay ram lambs (birth dates 12-30 April 1995) from the Duthie Farm flock (Rowett Research Institute) were weaned at 4 months of age in August (liveweight range 
$10.5-20.5 \mathrm{~kg}$ ). They were penned individually in natural light and for 18 weeks from 14 August were given a diet comprising $50 \%$ chopped hay, $30 \%$ rolled barley, $9 \%$ white fish meal, and molasses, minerals and vitamins (10 MJ metabolisable energy and $140 \mathrm{~g}$ crude protein $\mathrm{kg}^{-1}$ dry matter). Feeding was restricted to $0.35 \mathrm{~kg}$ dry weight head ${ }^{-1}$ day $^{-1}$ to prevent weight gain while maintaining liveweight (Group R), ad libitum (Group F), or restricted for 8 weeks followed by ad libitum feeding (Group R/F) ( $n=8$ per group). The refusal margin allowed for ad libitum-fed animals was $10 \%$ and intake varied between 1.5 and 2.25 times that of the restricted lambs. Each week, liveweight was recorded and blood samples were taken by jugular venepuncture into heparinized vacutainer tubes. Plasma was stored at $-20^{\circ} \mathrm{C}$ before analysis. Testicular growth was recorded each fortnight from 5 weeks onwards by measurement using vernier callipers of the maximum scrotal diameter across both testes, and the intensity of hyperaemia (sexual flush) of the abdominal skin close to the scrotum was scored subjectively on a scale of 0-5 (after Lincoln and Davidson, 1977).

\section{Radioimmunoassays}

LH concentrations were determined in duplicate using a radioimmunoassay kit provided by the National Institute of Digestive and Kidney Disorders (NIDDK, Rockville, MD) and expressed in terms of the reference standard NIDDK-oLH-1-2. Intra- and interassay coefficients of variation ( $\mathrm{CVs}$ ) averaged $9.5 \%$ and $6.0 \%$, respectively, at concentrations of $0.8,2.5$ and $6.9 \mathrm{ng} \mathrm{ml}^{-1}$, and the detection limit was $0.05 \mathrm{ng} \mathrm{ml}^{-1}$.

FSH concentrations were determined in duplicate using a radioimmunoassay kit (NIDDK) and expressed in terms of the reference standard NIDDK-oFSH-RP-1. Intra- and interassay CVs averaged, respectively, $5.5 \%$ and $5.7 \%$ at $1.7,3.2$ and $6.5 \mathrm{ng} \mathrm{ml}^{-1}$; the detection limit was $0.08 \mathrm{ng} \mathrm{ml}^{-1}$.

IGF-I was measured in duplicate neutralized formic acidethanol extracts of plasma by the radioimmunoassay method of Bruce et al. (1991), using human recombinant IGF-I (Bachem (UK) Ltd, Saffron Walden, Essex) for iodination and standards. Intra- and interassay CVs were $9.6 \%$ and $7.4 \%$, respectively, at 72 and $214 \mathrm{ng} \mathrm{ml}^{-1}$, and the detection limit was $34 \mathrm{ng} \mathrm{ml}^{-1}$.

Testosterone concentrations were determined in duplicate by the radioimmunoassay described by Adam et al. (1994). Intra- and interassay CVs were $10.9 \%$ and $10.5 \%$, respectively, at 1.7 and $7.5 \mathrm{ng} \mathrm{ml}^{-1}$, and the detection limit was $0.04 \mathrm{ng}$ $\mathrm{ml}^{-1}$.

\section{Statistical analyses}

Results were subjected to repeated measures analysis of variance to determine the effects of treatments and time. Linear correlation was used to examine associations between different parameters. Group means are presented \pm SEM. Total skin flush scores are presented for each group.

\section{Results}

There were significant effects of diet $(P<0.001)$, time $(P<0.001)$ and diet $x$ time interaction $(P<0.001)$ on live- weight; each group was significantly different from the others (Fig. Ia). There were also significant effects of $\operatorname{diet}(P<0.001)$, time $(P<0.001)$ and diet $\times$ time interaction $(P<0.001)$ on plasma IGF-I concentrations, with each group significantly different from the others (Fig. Ib). Liveweight and plasma IGF-I were very closely correlated $(r=0.96, P<0.001)$. IGF-I did not correlate with rate of liveweight gain $(r=0.24$, not significant).

Scrotal diameter was influenced by both diet $(P<0.01)$ and time $(P<0.001)$, with significant interaction between these effects $(P<0.001)$ (Fig. 1c). Values reached a peak in all groups after 11 weeks ( 30 October), before which Group F had higher values than Groups $R$ and $R / F$, and after which Group $F$ had higher values than Group $R$ but similar values to Group R/F. Scrotal diameter was correlated closely to liveweight $(r=0.78$, $P<0.001)$ and plasma IGF-I concentrations $(r=0.67$, $P<0.001)$, but not to FSH nor LH concentrations $(r=-0.02$ and 0.03 , respectively, not significant).

There were significant group $(P<0.01)$ and time $(P<0.001)$ effects on plasma testosterone concentrations (Fig. Id). Group $R$ had lower concentrations than Group $F$ throughout, whereas Group R/F had similar values to Group R before 10 weeks ( 23 October) and similar values to Group $\mathrm{F}$ thereafter. Testosterone correlated significantly with scrotal diameter $(r=0.68$, $P<0.001)$, plasma IGF-I $(r=0.67, P<0.001)$ and liveweight $(r=0.74, P<0.001)$, but not with FSH nor LH $(r=-0.34$ and -0.12 , respectively, not significant).

The sexual skin flush reached a maximum at the same time for each group, at 11 weeks ( 30 October), which coincided with maximum testis size (Fig. Ie).

Plasma FSH concentrations changed significantly with time $(P<0.001)$, showing seasonal maxima at 5 weeks (18 September, Groups $F$ and R/F) or 7 weeks (2 October, Group $R)$. They were influenced by $\operatorname{diet}(P<0.05)$ but this was highly dependent on time $(P<0.001)$ : Group $\mathrm{F}$ had higher values than the other two groups for the first 6 weeks $(P<0.001)$ but there were no group differences thereafter (Fig. If). Apart from a higher mean value at I week (2I August) $(P<0.05)$ in Group $\mathrm{F}$ than in Groups $\mathrm{R}$ and $\mathrm{R} / \mathrm{F}$, plasma $\mathrm{LH}$ was not significantly altered by diet or time (Fig. Ig). Overall, concentrations of FSH and LH were correlated $(r=0.58$; $P<0.001)$. Neither was correlated with plasma IGF-I concentrations.

\section{Discussion}

These results demonstrate a complex interaction between seasonal and nutritional cues in regulating activation of the hypothalamo-pituitary-testicular axis in pubertal Soay rams.

Peak testis size in the present study was observed in October, in agreement with Lincoln and Baker (1995). The pattern of increases in plasma FSH concentrations in autumn, followed by those in testis size, plasma testosterone and sexual skin flush, shown by the well-fed ram lambs was similar to the photoperiodically driven pattern exhibited by adult Soay rams (Lincoln and Short, 1980; Lincoln et al., 1990). The increases were of lower magnitude and reduced duration in the lambs, since they were initiated later in the year, but terminated at the same time as those in adults (Lincoln and Short, 1980; Lincoln et al., 1990). The effect of chronic nutritional growth restriction, 

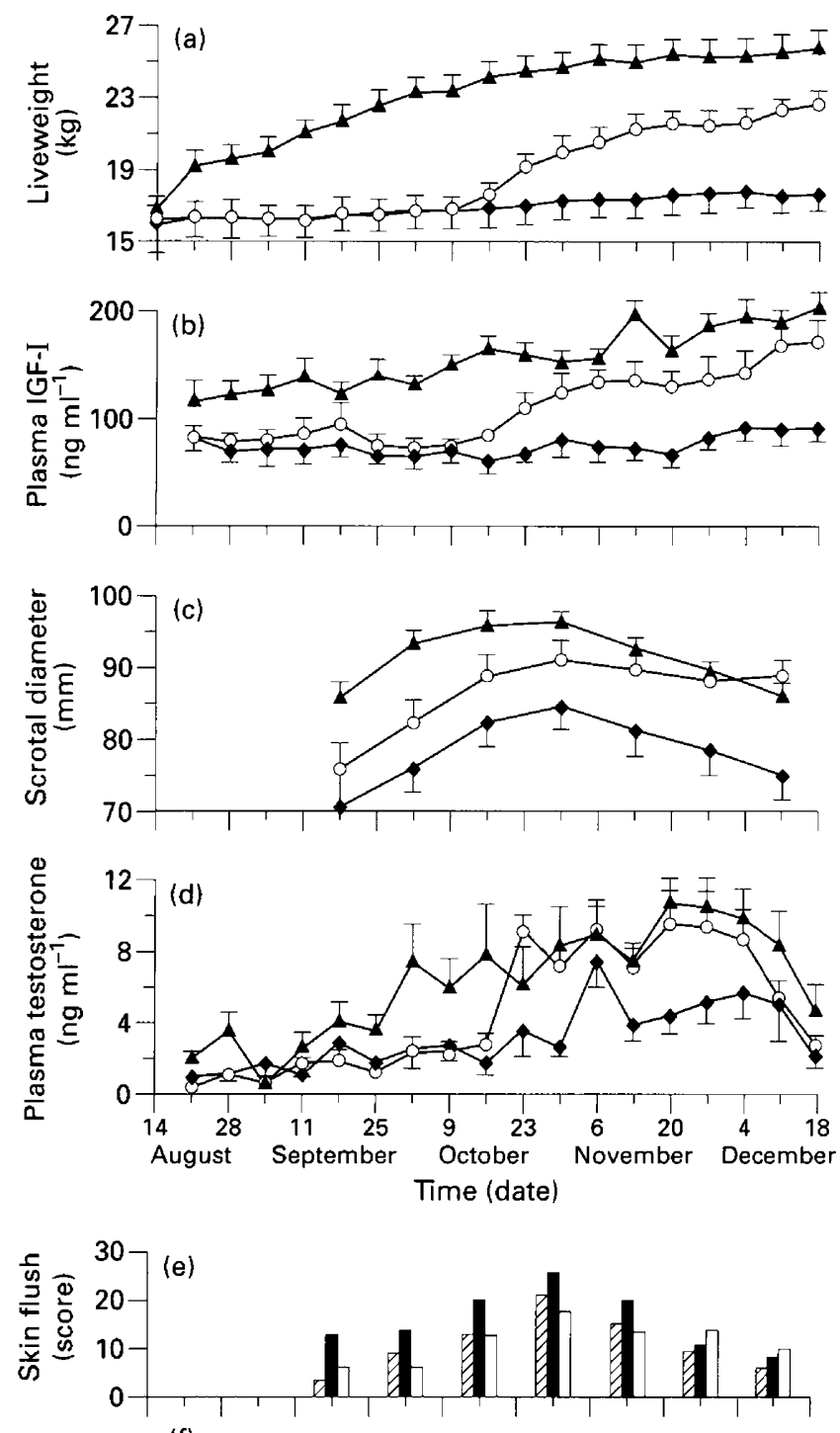

(f)
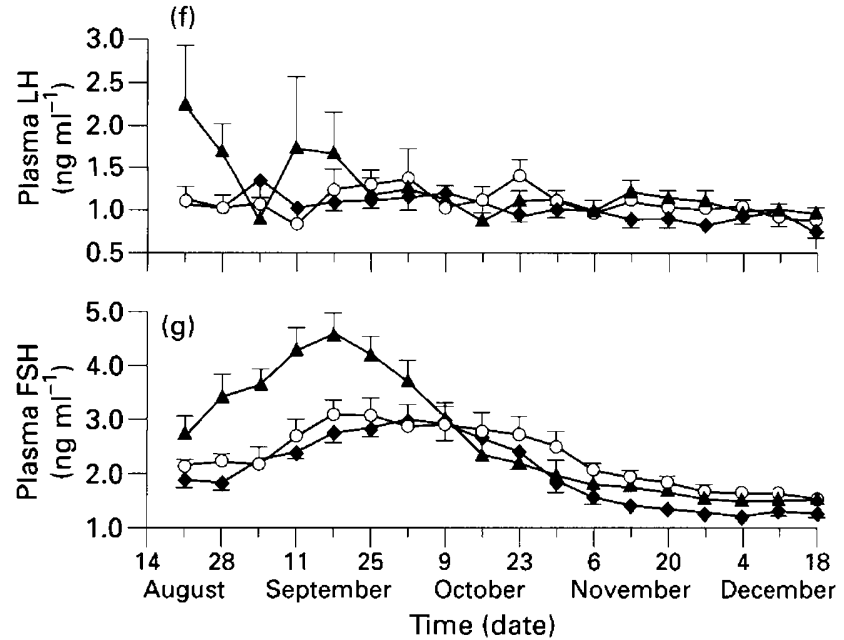

Fig. 1. Mean (a) liveweight, (b) plasma concentrations of insulin-like growth factor I (IGF-I), (c) scrotal diameter, (d) plasma testosterone, (e) intensity of sexual flush (total scores), and plasma concentrations of (f) $\mathrm{LH}$ and $(\mathrm{g}$ ) $\mathrm{FSH}$, in male Soay lambs given restricted (Group R, $\boldsymbol{\nabla}, 2$ ), unrestricted (Group F, $\mathbf{A}, \boldsymbol{\square}$ ) or restricted followed by unrestricted food (Group R/F, O, $\square$ ) for 18 weeks from 14 August. imposed on the Soay lambs approximately 10 weeks before peak testis development, reduced further the magnitude of these increases, without significantly affecting the timing of their peaks. These responses were consistent with the concept that reproductive development is an inevitable consequence of increasing postnatal age, though the rate of development depends on overall bodyweight and growth rate, and further development ceases at the same time of year irrespective of body growth. Thus the intensity of reproductive activation is dependent on nutritional status but its timing apparently remains under photoperiodic control.

Some more subtle seasonally dependent responses to increased nutritional status were also revealed in the present study. When compared with the lambs fed the restricted diet, the ad libitum-fed lambs had larger testes, greater testosterone secretion and more intense sexual skin flush at all stages from September to December, but increased gonadotrophin secretion only in the initial stages, in August to September. A similar transient increase in gonadotrophins is characteristic of the response to improved nutrition shown by adult Merino rams (Martin et al., 1994). However, a change from restricted to ad libitum feeding of the present ram lambs in October induced rapid recovery of testis size and testosterone secretion without a significant change in FSH nor LH output. (It is acknowleged that a change in LH pulse frequency would not have been detected by the sampling schedule used, but very large increases in pulse rate would be expected to raise baseline values that were detectable, as in the early ad libitum-fed group.) This finding suggests that there was an age-related or seasonal downwards shift in nutritional sensitivity along the hypothalamo-pituitary-testicular axis, and also that direct nutritional stimulation of testis growth occurred without alterations in gonadotrophin secretion. Seasonal alterations in gonadotrophin responses to different nutritional regimens have also been observed in adult goat bucks (Walkden-Brown et al., 1994). These changes were attributed to seasonal alterations in the amount of photoperiodic inhibition of the gonadotrophic axis since alterations in hypothalamo-pituitary gonadotrophin output mediate the photoperiodically driven reproductive cycle in seasonal male ruminants (Lincoln and Short, 1980). The present ram lambs showed hypothalamo-pituitary responsiveness to improved nutrition in the early autumn, but this was absent, or much reduced, a few weeks later. Since hypothalamo-pituitary sensitivity to gonadal steroid inhibitory feedback decreases during pubertal development (Olster and Foster, 1986) and alters seasonally in adults (Legan and Karsch, 1980), it may have been a limiting factor, responsive to nutrition, in August-September but not in the older lambs in October.

The seasonal cycle of testis size and testosterone secretion characteristically parallels that of FSH in adult rams, in both the highly seasonal Soays and the less seasonal Merinos (Lincoln et al., 1990). Changes in gonadotrophin secretion are thought to drive both the seasonal sexual cycle of adult Soay rams (Lincoln and Short, 1980) and puberty in ram lambs (Olster and Foster, 1986). The nutritionally induced testicular growth in adult Merinos is mediated in part by nutritional stimulation of both FSH and LH (Martin et al., 1994), and this mechanism could underlie the early difference in testis size in September between the present ad libitum-fed and restricted groups of 
lambs. However, the effects of improved nutrition on testicular size in both adult Merinos (Martin et al., 1994) and the present pubertal Soays cannot be explained fully by changes in gonadotrophin output. Rather, the increased testicular size in the absence of a significant change in circulating gonadotrophins in the group given ad libitum feeding in October was attributable to gonadotrophin-independent stimulation of the gonads (as in the rams of Martin et al. (1994)) and increased testicular responsiveness to gonadotrophins or both. Testicular responsiveness to gonadotrophins is increased during the breeding season of adult Soays, as demonstrated by increased testosterone release in response to $\mathrm{LH}$ (Lincoln and Short, 1980). Testosterone secretion was closely correlated with testis size in the present lambs, unlike in adult rams and bucks (Martin et al., 1994; Walkden-Brown et al., 1994). The nutritioninduced increase in testosterone secretion in the October ad libitum lambs occurred without a measurable increase in $\mathrm{LH}$ concentrations, consistent with seasonally heightened testicular responsiveness to LH (Lincoln and Short, 1980). Conversely, testicular steroidogenesis was not stimulated by improved nutrition in adult Merinos, nor was testosterone release in response to $\mathrm{LH}$ enhanced (Martin et al., 1994; Hotzel et al., 1995). Therefore, in the absence of changes in circulating gonadotrophins, nutritional signals may therefore act on the somatic compartment of the testis irrespective of age, but only act on its steroidogenic function during pubertal development; thus, the spermatogenic and endocrine functions of the testis may be integrated during pubertal development but become dissociated in adulthood.

It is tempting to speculate that circulating IGF-I may have mediated some of the present nutritional effects on the pubertal reproductive axis. Plasma IGF-I concentrations were positively correlated with liveweight and, as is the case during nutritionally modulated pubertal reproductive development in bulls (Renaville et al., 1993) and stags (Adam et al., 1995), with plasma testosterone concentrations. However, the relationship between these two hormones is equivocal, with evidence available to suggest that they are secreted independently in bulls (Renaville et al., 1996), that testosterone regulates IGF-I at puberty in baboons (Crawford and Handelsman, 1996), and that IGF-I regulates testicular steroidogenesis in men (Spiteri-Grech and Nieschlag, 1992). Receptors for IGF-I are present on virtually all cell types in the body (Jones and Clemmons, 1995), including Sertoli and Leydig cells (Nagpal et al., 1991; Borland et al., 1984). Given that IGF-I is also produced locally in the testis, some of its actions may also be autocrine or paracrine rather than endocrine (Spiteri-Grech and Nieschlag, 1992) but, significantly, these actions include upregulation of LH-binding sites on Leydig cells (Bernier et al., 1986) and could provide an explanation for the heightened sensitivity of testosterone release to unchanging circulating LH. Alternatively, IGF-I may have provided direct gonadotrophin-independent stimulation of steroidogenesis, as well as promoting testicular growth through its characteristic anabolic and mitogenic actions (Jones and Clemmons, 1995).

An action of IGF-I at the hypothalamo-pituitary axis cannot be discounted from the present results. The increase in gonadotrophin output shown in August by the ad libitum-fed group may have been stimulated by the increased circulating IGF-I either directly (Hiney et al., 1996; C. L. Adam, un- published) or via decreased hypothalamo-pituitary sensitivity to sex steroid negative feedback (Wilson, 1995). A decrease in sensitivity to gonadal steroid inhibition of LH secretion is a prerequisite for the final stages of ovine pubertal development (Olster and Foster, 1986) and also underlies the photoperiodically driven transition into the breeding season of adult sheep (Legan and Karsch, 1980). Therefore, the lack of gonadotrophin stimulation by increased circulating IGF-I in October in the present lambs could have been because sensitivity to sex steroid negative feedback was no longer a limiting factor at this time and had already undergone a seasonal or age-related decrease. Whether or not the timing of this decrease is normally determined by photoperiod (Wood et al., 1991b), it can apparently be advanced by increased IGF-I in sheep (present study) as it is in primates (Wilson, 1995).

Thus, nutrition during the latter stages of pubertal development appears to modulate the intensity of reproductive endocrine and gonadal activation in Soay males, though not the timing of peak development, via direct effects on the testes and seasonally dependent effects on the hypothalamo-pituitary axis. These effects may be mediated by circulating IGF-I.

This work was funded by the Scottish Office Agriculture Environment and Fisheries Department. The authors thank the staff of the Duthie Farm for their daily care of the animals, NIDDK for providing RIA reagents, and T. Atkinson for carrying out LH, FSH and IGF-I iodinations for the radioimmunoassays.

\section{References}

Adam CL, Kyle CE and Young P (1994) Influence of prenatal photoperiod on postnatal reproductive development in male red deer (Cervus elaphus) Journal of Reproduction and Fertility 100 607-611

Adam CL, Kyle CE, Young $\mathbf{P}$ and Atkinson T (1995) Effect of nutritional growth restriction on timing of reproductive development and plasma concentrations of insulin-like growth factor-1 and growth hormone in male red deer (Cervus elaphus) reared in constant photoperiod Animal Science 61 155-160

Bernier M, Chatelain P, Mather, JP and Saez JM (1986) Regulation of gonadotropin receptors, gonadotropin responsiveness and cell multiplication by somatomedin $\mathrm{C}$ and insulin in cultured pig Leydig cells Journal of Cell Physiology 129 257-263

Borland K, Mita M, Oppenheimer CL, Blinderman LA, Massague J, Hall PF and Czech MP (1984) The actions of insulin-like growth factors I and II on cultured Sertoli cells Endocrinology 114 240-246

Bruce LA, Atkinson T, Hutchinson JSM, Shakespear RA and MacRae JC (1991) The measurement of insulin-like growth factor 1 in sheep plasma Journal of Endocrinology 128 R1-R4

Crawford BA and Handelsman DJ (1996) Androgens regulate circulating levels of insulin-like growth factor (IGF-I) and IGF binding protein-3 during puberty in male baboons Joumal of Clinical Endocrinology and Metabolism $\mathbf{8 1}$ $65-72$

Dýrmundsson OR (1973) Puberty and early reproductive performance in sheep. II. Ram lambs Animal Breeding Abstracts 41 419-427

Hiney JK, Srivastava V, Nyberg CL, Ojeda SR and Dees WL (1996) Insulin-like growth factor $I$ of peripheral origin acts centrally to accelerate the initiation of female puberty Endocrinology 137 3717-3728

Hotzel MJ, Walkden-Brown SW, Blackberry MA and Martin GB (1995) The effect of nutrition on testicular growth in mature Merino rams involves mechanisms that are independent of changes in GnRH pulse frequency Journal of Endocrinology 147 75-85

Jones JI and Clemmons DR (1995) Insulin-like growth factors and their binding proteins: biological actions Endocrine Reviews 16 3-34

Legan SJ and Karsch FJ (1980) Photoperiodic control of seasonal breeding in the ewe: modulation of the negative feedback action of estradiol Biology of Reproduction 23 1061-1068 
Lincoln GA and Baker BI (1995) Seasonal and photoperiod-induced changes in the secretion of $\alpha$-melanocyte-stimulating hormone in Soay sheep: temporal relationships with changes in $\beta$-endorphin, prolactin, follicle-stimulating hormone, activity of the gonads and growth of wool and horns Journal of Endocrinology 144 471-48I

Lincoln GA and Davidson W (1977) The relationship between sexual and aggressive behaviour, and pituitary and testicular activity during the seasonal sexual cycle of rams and the influence of photoperiod journal of Reproduction and Fertility 49 267-276

Lincoln GA and Short RV (1980) Seasonal breeding: Nature's contraceptive Recent Progress in Hormone Research 36 1-51

Lincoln GA, Lincoln CE and McNeilly AS (1990) Seasonal cycles in the blood plasma concentration of $\mathrm{FSH}$, inhibin and testosterone, and testicular size in rams of wild, feral and domesticated breeds of sheep Journal of Reproduction and Fertility 88 623-633

Martin GB, Tjondronegoro S and Blackberry MA (1994) Effects of nutrition on testicular size and the concentrations of gonadotrophins, testosterone and inhibin in plasma of mature male sheep Journal of Reproduction and Fertility 101 121-128

Nagpal ML, Wang D, Calkins JH, Chang W and Lin T (1991) Human chorionic gonadotropin up-regulates insulin-like growth factor-1 receptor gene expression of Leydig cells Endocrinology 129 2820-2826

Olster DH and Foster DL (1986) Control of gonadotropin secretion in the male during puberty: a decrease in response to steroid inhibitory feedback in the absence of an increase in steroid-independent drive in the sheep Endocrinology 118 2225-2234
Pretorius PS and Marincowitz G (1968) Post-natal penis development, testis descent and puberty in Merino ram lambs on different planes of nutrition South African Journal of Agricultural Science 11 319-334

Renaville R, Devolder A, Massart S, Sneyers M, Burny A and Portetelle D (1993) Changes in the hypophysial-gonadal axis during the onset of puberty in young bulls Journal of Reproduction and Fertility $99443-449$

Renaville R, Massart S, Sneyers M, Falaki M, Gengler N, Burny A and Portetelle D (1996) Dissociation of increases in plasma insulin-like growth factor $I$ and testosterone during the onset of puberty in bulls Joumal of Reproduction and Fertility 106 79-86

Spiteri-Grech J and Nieschlag E (1992) The role of growth hormone and insulin-like growth factor 1 in the regulation of male reproductive function Hormone Research 38 22-27

Walkden-Brown SW, Restall BJ, Norton BW, Scaramuzzi RJ and Martin GB (1994) Effect of nutrition on seasonal patterns of LH, FSH and testosterone concentration, testicular mass, sebaceous gland volume and odour in Australian cashmere goats Journal of Reproduction and Fertility 102 351-360

Wilson ME (1995) IGF-I administration advances the decrease in hypersensitivity to oestradiol negative feedback inhibition of serum LH in adolescent female rhesus monkeys Journal of Endocrinology 145 121-130

Wood RI, Ebling FJP and Foster DL (1991a) Sex differences in nutritional modulation of gonadotropin secretion during development: studies in the growth retarded lamb Biology of Reproduction 44 632-639

Wood RI, Ebling FJP, I'Anson H and Foster DL (1991b) The timing of neuroendocrine sexual maturity in the male lamb by photoperiod Biology of Reproduction 45 82-88 